\title{
The Role of Catalase-Peroxidase Secreted by Magnaporthe oryzae During Early Infection of Rice Cells
}

\author{
Shigeru Tanabe, ${ }^{1}$ Naoko Ishii-Minami, ${ }^{1}$ Ken-Ichiro Saitoh, ${ }^{1,2}$ Yuko Otake, ${ }^{1}$ Hanae Kaku, ${ }^{3}$ Naoto Shibuya, ${ }^{3}$ \\ Yoko Nishizawa, ${ }^{1}$ and Eiichi Minami ${ }^{1}$ \\ ${ }^{1}$ Division of Plant Sciences, National Institute of Agrobiological Sciences, 2-1-2 Kannondai, Tsukuba, 305-8602, Japan; \\ ${ }^{2}$ Advanced Career Development Center for Agro-Innovation, Tokyo University of Agriculture and Technology, 3-5-8 Saiwai-cho, \\ Fuchu, 183-8509, Japan; ${ }^{3}$ Department of Life Sciences, Meiji University, 1-1-1 Higashi-Mita, Tama-ku, Kawasaki, 214-8571, \\ Japan
}

Submitted 30 July 2010. Accepted 26 October 2010.

\begin{abstract}
The biological role of a secretory catalase of the rice blast fungus Magnaporthe oryzae was studied. The internal amino acid sequences of the partially purified catalase in the culture filtrate enabled us to identify its encoding gene as a catalase-peroxidase gene, $C P X B$, among four putative genes for catalase or catalase-peroxidase in $M$. oryzae. Knockout of the gene drastically reduced the level of catalase activity in the culture filtrate and supernatant of conidial suspension (SCS), and increased the sensitivity to exogenously added $\mathrm{H}_{2} \mathrm{O}_{2}$ compared with control strains, suggesting that $C P X B$ is the major gene encoding the secretory catalase and confers resistance to $\mathrm{H}_{2} \mathrm{O}_{2}$ in hyphae. In the mutant, the rate of appressoria that induced accumulation of $\mathrm{H}_{2} \mathrm{O}_{2}$ in epidermal cells of the leaf sheath increased and infection at early stages was delayed; however, the formation of lesions in the leaf blade was not affected compared with the control strain. These phenotypes were complimented by reintroducing the putative coding regions of $C P X B$ driven by a constitutive promoter. These results suggest that $C P X B$ plays a role in fungal defense against $\mathrm{H}_{2} \mathrm{O}_{2}$ accumulated in epidermal cells of rice at the early stage of infection but not in pathogenicity of $M$. oryzae.
\end{abstract}

The generation of reactive oxygen species (ROS) such as the superoxide anion radical $\left(\mathrm{O}_{2}^{-}\right)$, hydroxyl radical $\left(\mathrm{OH}^{-}\right)$, and hydrogen peroxide $\left(\mathrm{H}_{2} \mathrm{O}_{2}\right)$ in plant cells is one of the most rapid and drastic defense reactions activated following pathogen attack (Doke 1983; Lamb and Dixon 1997). $\mathrm{H}_{2} \mathrm{O}_{2}$ is involved in the cross-linking of cell wall proteins, induction of expression of defense-related genes, and production of phytoalexins (Bradley et al. 1992; Chai and Doke 1987; Torres and Dangl 2005; Torres et al. 2006). It has been suggested that $\mathrm{H}_{2} \mathrm{O}_{2}$ mediates mutual interactions between pathogens and host plants through its fungicidal and bactericidal effects ( $\mathrm{Lu}$ and Higgins 1999; Peng and Kuc 1992). Hyphal growth of some biotrophic and hemibiotrophic fungal pathogens is inhibited in the host cells because of $\mathrm{H}_{2} \mathrm{O}_{2}$ produced by the host (Mellersh et al. 2002; Shetty et al. 2007; Thordal-Christensen et al. 1997; Vanacker et al. 2000), whereas the growth of necrotrophic fungal pathogens is enhanced in the presence of $\mathrm{H}_{2} \mathrm{O}_{2}$ (Able 2003; Govrin and Levine 2000; Kumar et al. 2001). In such oxidative environments, ROS-degrading enzymes could play crucial roles for the survival of pathogens. In fact,

Corresponding author: E. Minami; Telephone: +81-29-838-7912; Fax: +81-29-838-7912; E-mail: eiminami@affrc.go.jp catalase-deficient mutants of Claviceps purpurea, Botrytis cinerea, and Cochliobolus heterostrophus show increased sensitivity to $\mathrm{H}_{2} \mathrm{O}_{2}$ in vitro. However, none of these mutants showed altered pathogenicity; inoculation of these mutants resulted in the formation of lesions of normal size and frequency (Garre et al. 1998; Robbertse et al. 2003; Schouten et al. 2002).

The hemibiotrophic fungus Magnaporthe oryzae causes the most serious disease of rice worldwide (Talbot 2003). After the conidia of $M$. oryzae contact the surface of a rice leaf, germ tubes emerge from the conidia, and the tip of the tube swells to form an appressorium, which is a penetration structure into rice cells. The hyphal penetration peg elongates from the mature appressorium into the rice cell (Howard and Valent 1996; Tucker and Talbot 2001). During this process, $\mathrm{H}_{2} \mathrm{O}_{2}$ accumulates in the rice tissues infected with $M$. oryzae (Kato et al. 2009; Kawasaki et al. 1999). It remains to be elucidated how $\mathrm{H}_{2} \mathrm{O}_{2}$ accumulation is involved in the interaction between $M$. oryzae and rice cells at infection sites.

The genome sequence of $M$. oryzae (Dean et al. 2005) predicts four catalase genes: that is, two monofunctional catalase genes (CATA, MG100061.6 and CATB, MG06442.6) and two bifunctional catalase-peroxidase genes (CPXA, MG04337.6 and $C P X B$, MG09834.6), as designated by Skamnioti and associates (2007) who showed that a putative secretory catalase, CATB, is involved in pathogenicity not via detoxification of host-produced $\mathrm{H}_{2} \mathrm{O}_{2}$ but by maintaining the integrity of the cell wall (Skamnioti et al. 2007). Therefore, it remains unclear whether $M$. oryzae has $\mathrm{H}_{2} \mathrm{O}_{2}$ detoxification systems in order to cope with the host oxidative burst and how these systems are involved in the host-fungus interaction.

In this study, we detected a catalase encoded by the $C P X B$ gene in the culture filtrate of $M$. oryzae. To elucidate the role of $C P X B$ at the early stage of infection, a knock-out mutant of this gene was generated, and its sensitivity to $\mathrm{H}_{2} \mathrm{O}_{2}$ and pathogenicity were analyzed.

\section{RESULTS}

Partial purification of a secreted catalase and identification of the encoding gene.

We previously reported that the supernatant of conidial suspension (SCS) prepared from $M$. oryzae grown on a nutritional medium includes catalase activity (Tanabe et al. 2008). The results prompted us to seek catalase activity in culture filtrates of $M$. oryzae. Preliminary experiments indicated that $\mathrm{H}_{2} \mathrm{O}_{2}$-degrading activity was detected at 10 to 15 days postinoculation 
(dpi) in yeast-glucose (YG) medium (data not shown), and we partially purified the protein by column chromatography. Coomassie staining of the gel after sodium dodecyl sulfate polyacrylamide gel electrophoresis (SDS-PAGE) revealed a single band whose mobility was indistinguishable from that of a catalase-active band. This single band was excised, digested with lysyl endopeptidase to obtain a partial amino acid sequence, and analyzed. We obtained two amino acid sequences from a single digested fragment, LVGEEGPQLYVSHGG (major signal; peptide number 1) and ATMLTSDLALINDPE (minor signal; peptide number 2). A BLAST search for these peptide

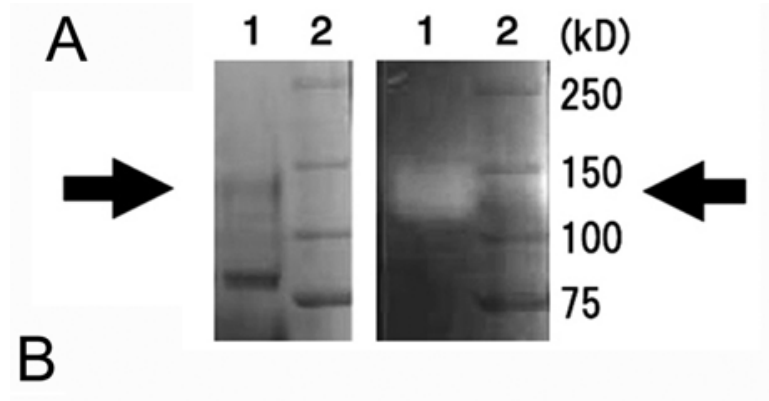

sequences showed that peptides numbers 1 and 2 corresponded to residues 791 to 804 on the predicted amino acid sequence of $M$. oryzae $\beta$-glucosidase 1 (accession number MG09272.6) and residues 418 to 432 of catalase-peroxidase (Fig. 1B, CPXB; accession number MG09834.6), respectively. These results showed that both $\beta$-glucosidase 1 and $\mathrm{CPXB}$ co-migrate on SDS-PAGE and indicate that $C P X B$ encodes the catalase secreted into the culture medium.

The apparent molecular weight (MW) estimated from the mobility on SDS-PAGE was $125 \mathrm{kDa}$, which remained unchanged after boiling or treatment with dithiothreitol at $50 \mathrm{mM}$ before electrophoresis (data not shown). $C P X B$ encodes 786 amino acids, and the calculated MW is $85,585 \mathrm{Da}$ in M. oryzae isolate 70-15. In silico analysis of the cellular localization (PSORT) predicted that CPXB is an extracellular protein with a single cleavage site of the signal sequence at positions 16 and 17 in the $N$-terminal region (Fig. 1B).

\section{Generation of $C P X B$ disruption mutants.}

To analyze the biological role of $\mathrm{CPXB}, C P X B$ disruptants were generated by the Agrobacterium-mediated transformation method (Saitoh et al. 2008). We amplified the two genomic DNA fragments corresponding to positions 1 to 194 and 414 to 786 in the amino acid sequence and constructed a plasmid pCAMBIA-CPXB-KO that was introduced into Ina86-137 via Agrobacterium spp. to induce homologous recombination (Fig. 2A). Total DNA was isolated from the hygromycin-resistant transformants, digested with EcoRI/EcoRV or NcoI, and subjected to Southern blot analysis. The sizes of detected DNA fragments were consistent with those predicted from the restriction map of $C P X B$ and pCAMBIA-CPXB-KO (Fig. 2B), indicating that the targeted replacement of $C P X B$ occurred correctly in the five candidates $(\triangle C P X B$; numbers $14-1,17-1,22-3$, 28-1, 111-1) (Fig. 2B). The putative amino acid sequence of CPXB contains two peroxidase motifs at 132 to 143 (GGLFVRMAWHSA) and 306 to 316 (TVALIAGGHAF) (Fig. 1B). Therefore, in these strains, the DNA sequence encoding the second peroxidase motif was expected to have been deleted. Among these, number 22-3 was transformed with pCAMBIA- $c C P X B$ constructed for the complementation of $C P X B$, in which the genomic DNA fragment of $C P X B$ relevant to the putative protein coding region, including $219 \mathrm{bp}$ of the 5'-flanking region, was fused with PtrpC promoter and Tnos terminator (Fig. 2C). We used this promoter because we could not amplify the 5'-upstream region of $C P X B$ of Ina86-137. A bialaphos-resistant line, R12-3 (designated as $c C P X B$ ), was subjected to Southern blot analysis, and the probed size of DNA fragments after digestion with EcoRI/EcoRV indicated that the chromosomal insertion of the constructed gene properly occurred (Fig. 2D).

The five strains of $\triangle C P X B$ were almost normal with respect to conidiation, conidial germination, rates of appressorium formation on plastic slips, and rate of penetration into onion epidermal cells (data not shown).

Fig. 1. In-gel staining of catalase activity. A, Sodium dodecyl sulfate polyacrylamide gel electrophoresis (SDS-PAGE) of partially purified catalase from culture filtrate and in-gel detection of the activity. The partially purified fraction from P91-15B containing catalase activity was divided into two aliquots and separated by SDS-PAGE on a 5 to $20 \%$ polyacrylamide gel ( $5 \mu \mathrm{g}$ of protein/lane) together with prestained molecular weight markers. After electrophoresis, the gel was separated into two parts and stained with Coomassie Brilliant Blue R-250 (left panel) and stained for catalase (right panel), respectively. Lane 2 in each panel shows the molecular weight standard as indicated on the right. Arrows indicate the catalaseactive band. B, Primary amino acid sequence of CPXB. Dotted, underlined, and doubly underlined amino acids indicate regions of putative signal peptide, a region removed in the knock-out mutants, and the amino acid sequence obtained by Edman degradation method, respectively. Black- and gray-shadowed letters are peroxidase motif and potential $\mathrm{N}$ glycosylation site, respectively.

\section{Extracellular activity of catalase and sensitivity to $\mathrm{H}_{2} \mathrm{O}_{2}$ in $\triangle C P X B$.}

The mutants were tested for extracellular activity of catalase. Hyphae of the $\triangle C P X B, c C P X B$, and the control strain were grown on nylon membranes laid on potato dextrose agar (PDA) plates for 5 days, the membranes were removed, and the agar plates were stained for catalase activity. In the control strain and $c C P X B$, catalase activity was detected as a lightgreen stain whereas, in the $\triangle C P X B$ strains, the activity was significantly diminished (Fig. 3A). We previously reported that SCS includes catalase activity, and it was not clear whether the activity in SCS was due to $C P X B$. We examined the $\mathrm{H}_{2} \mathrm{O}_{2}$-de- 
grading activity not only in culture filtrates in YG medium but also in SCS of $\triangle C P X B$ strains, all of which showed much less activity of catalase in vitro than the control strain or $c C P X B$ (Fig. 3B and C). The sensitivity of $\triangle C P X B$ to $\mathrm{H}_{2} \mathrm{O}_{2}$ was examined. Hyphae of $\triangle C P X B, c C P X B$, and the control strain were incubated on PDA agar plates containing $\mathrm{H}_{2} \mathrm{O}_{2}$, and the diameter of the colonies was measured after 5 days. The $\triangle C P X B$ strains showed growth comparable with that of control strain in the absence of $\mathrm{H}_{2} \mathrm{O}_{2}$. At $1 \mathrm{mM} \mathrm{H}_{2} \mathrm{O}_{2}$, the growth of $\triangle C P X B$ strains was slightly inhibited compared with the control strains. $\mathrm{H}_{2} \mathrm{O}_{2}$ at $5 \mathrm{mM}$ strongly inhibited the growth of $\triangle C P X B$ strains, while the growth of the control strain and $c C P X B$ strain exhibited approximately 50\% inhibition (Fig. 3D and E). These results strongly suggested that $\mathrm{CPXB}$ is a major secreted catalase of $M$. oryzae for the degradation of extracellular $\mathrm{H}_{2} \mathrm{O}_{2}$, conferring resistance against $\mathrm{H}_{2} \mathrm{O}_{2}$ during vegetative growth. In these experiments, ectopic strains showed the same results as those of the control and $c C P X B$ strains (data not shown). Because the five $\triangle C P X B$ strains exhibited the same levels of extracellular catalase activity, we used numbers $14-1$, $17-1$, and 22-3 in the following experiments.

\section{Role of $C P X B$ on infection of $M$. oryzae to epidermal cells of rice leaf sheaths.}

We previously reported that the level of $\mathrm{H}_{2} \mathrm{O}_{2}$ in the epidermal cells of rice leaf sheath is reduced after inoculation of conidia in the presence of SCS that includes catalase activity (Tanabe et al. 2008, 2009). Catalase activity in SCS was due to CPXB (Fig. 3C); thus, it was indicated that preexisting CPXB in the conventionally prepared conidia suspension is responsible for the degradation of $\mathrm{H}_{2} \mathrm{O}_{2}$ during infection in rice. To evaluate the role of $C P X B$ in the quenching of $\mathrm{H}_{2} \mathrm{O}_{2}$ during the infection, conidia of $\triangle C P X B \mathrm{~s}$ and the control strain were washed by successive centrifugation to remove preexisting $\mathrm{CPXB}$, resuspended in water, and inoculated on leaf sheaths of rice. The accumulation of $\mathrm{H}_{2} \mathrm{O}_{2}$ was examined around the penetration sites in the epidermal cells of leaf sheaths at $24 \mathrm{~h}$ postinoculation (hpi) by 3',3-diaminobenzidine tetrahydrochloride (DAB) staining. The pattern of DAB staining in response to the inoculation with Ina86-137 was indistinguishable from those inoculated with $\triangle C P X B$ strains (Fig. 4A). Inoculation of $\triangle C P X B$ strains induced a slightly but significantly higher rate of DAB signal-positive cells than in the control

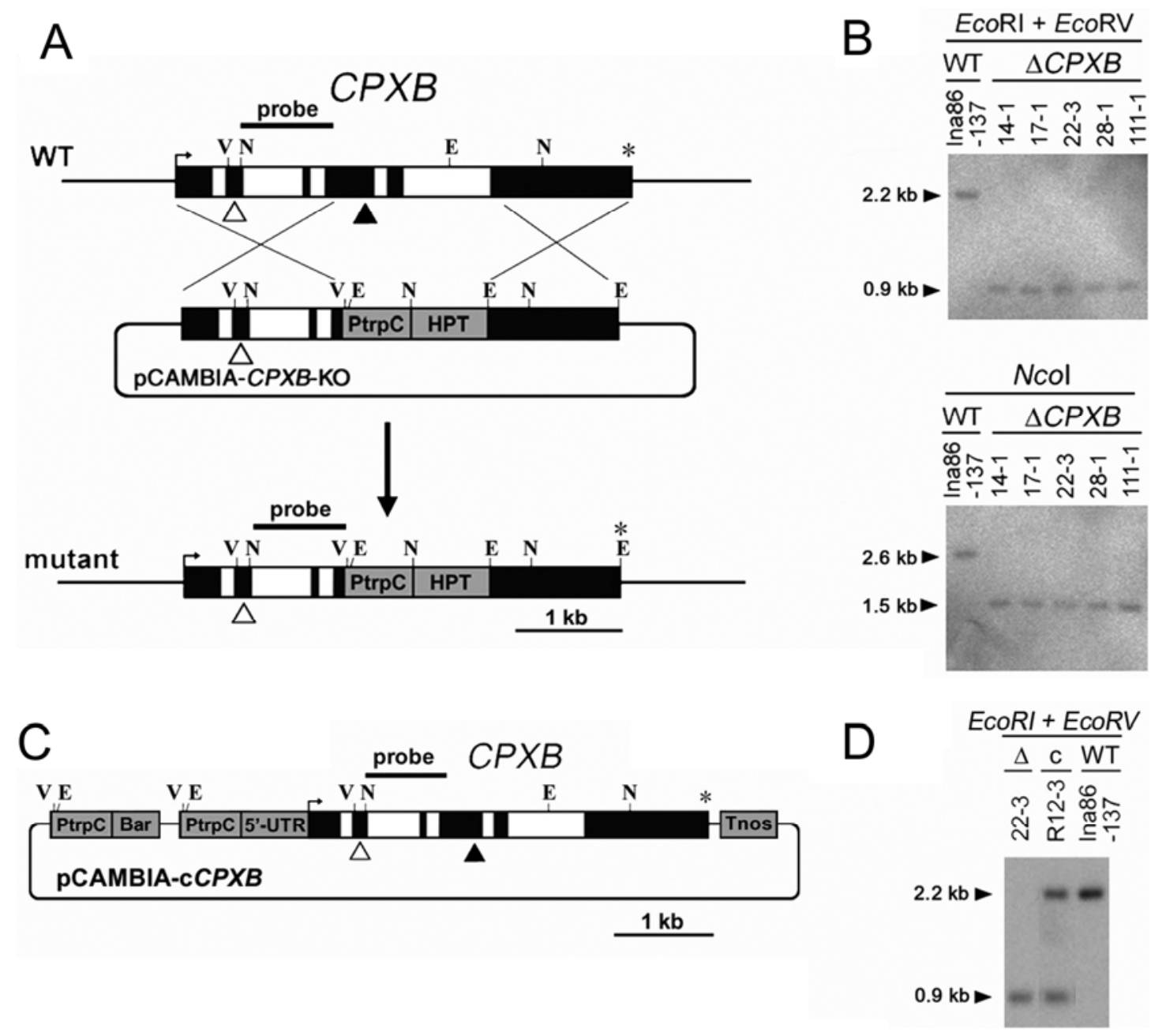

Fig. 2. Targeted gene disruption of $C P X B$. A, Schematic diagram of genomic organization of the $C P X B$ locus before (wild-type strain [WT]) and after (mutant) disruption. Organization of the exon (closed bar) and intron (open bar) with the translational start (arrow) and termination (asterisk) sites indicated. Closed and open triangles indicate the putative heme-binding motifs. Restriction sites used for Southern analysis are indicated as N ( $N c o I), \mathrm{V}(E c o R V)$, and E (EcoRI). HPT; hygromycin phosphotransferase. B, Southern blot analysis of the genomic DNA of the WT strain and selected transformants $(\triangle C P X B)$. Genomic DNA $(1 \mu \mathrm{g})$ was digested with $E c o \mathrm{RI} / E c o$ RV (upper panel) or $N c o I$ (lower panel), separated by agarose gel electrophoresis, and blotted onto a nylon membrane, which was hybridized with a ${ }^{32} \mathrm{P}$-labeled 770-bp fragment ("probe" in A and C). C, Schematic diagram of pCAMBIA- $c C P X B$ for the construction of the complemented strain. Organization of the exon (closed bar) and intron (open bar) with the translational start (arrow) and termination (asterisk) sites indicated. Restriction sites used for Southern analysis are indicated as V $(E c o R V)$ and E (EcoRI). D, Southern blot analysis of the genomic DNA of the recipient of pCAMBIA-cCPXB (no. 22-3), transformed strain (R12-3), and the control strain (WT; Ina86-137). Genomic DNA (1 $\mu \mathrm{g}$ ) was digested with EcoRI/EcoRV, separated by agarose gel electrophoresis, and blotted onto a nylon membrane, which was hybridized with a ${ }^{32} \mathrm{P}$-labeled 770-bp fragment ("probe" in A and C). 
strain or $c C P X B$ (Fig. 4B). These results indicate that $\mathrm{CPXB}$ is secreted from the infectious hyphae and reduces the level of $\mathrm{H}_{2} \mathrm{O}_{2}$ accumulated in the epidermal cells of rice.

To investigate the role of $C P X B$ in pathogenicity, $\triangle C P X B$, $c C P X B$, and the control strain were inoculated on leaf sheaths of rice. Appressoria on the epidermis of leaf sheaths were observed at 20,29, and 48 hpi using microscopy and the extent of infection was scored as "multi-cells" and "one-cell", corresponding to the infection site where infectious hyphae are observed in more than one cell or one cell, respectively, of the leaf sheath of rice (Fig. 5A). The percentage of One-cell infection by $\triangle C P X B$ strains at $20 \mathrm{hpi}$ was significantly lower than that of the control strains (Fig. 5B). No Multi-cell infection sites were observed at this stage. At 29 hpi, the percentage of the Multi-cell infection by the $\triangle C P X B$ strains significantly decreased compared with that in the control strain or $c C P X B$, and the difference in percentage disappeared at $48 \mathrm{hpi}$. At $6 \mathrm{dpi}$, inoculation of $\triangle C P X B, c C P X B$, and the control strain formed lesions of similar sizes in leaf blades (Fig. 5C). These results suggest that CPXB supports the growth of infectious hyphae at the early stage of infection.

In the experiments of Figures 4 and 5, ectopic strains showed the same results as those of the control and $c C P X B$ strains (data not shown).

Expression of $C P X B$ during infection in leaf sheath of rice.

Skamnioti and associates (2007) examined the levels of mRNAs for $C A T A, C A T B, C P X A$, and $C P X B$ after inoculation
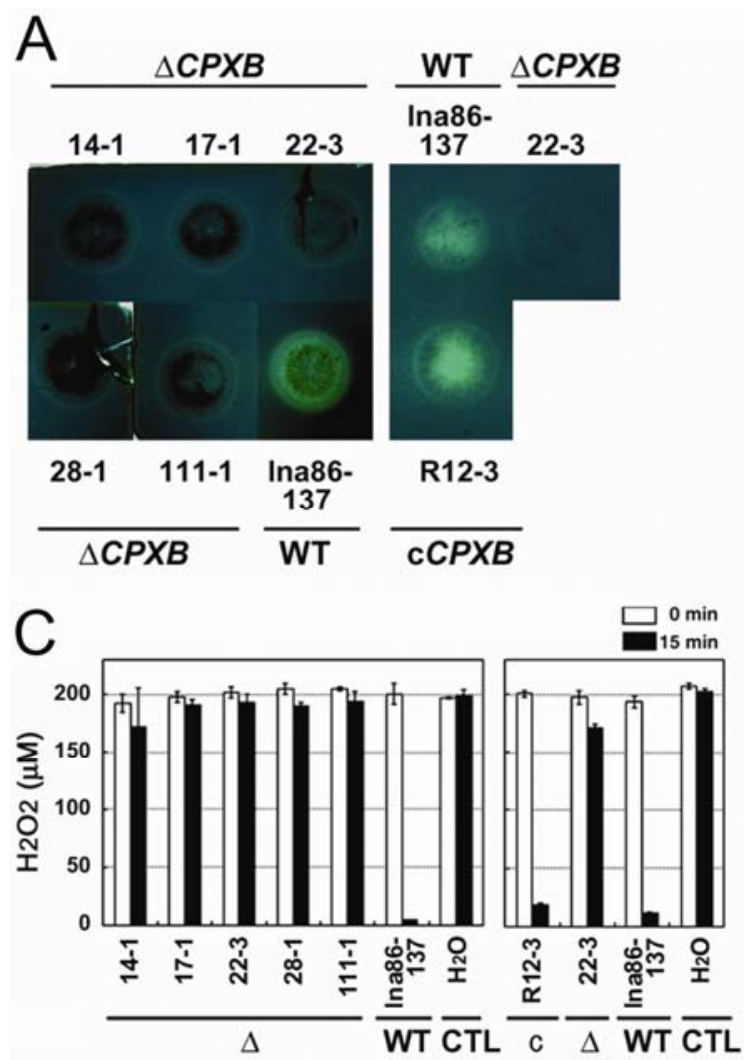
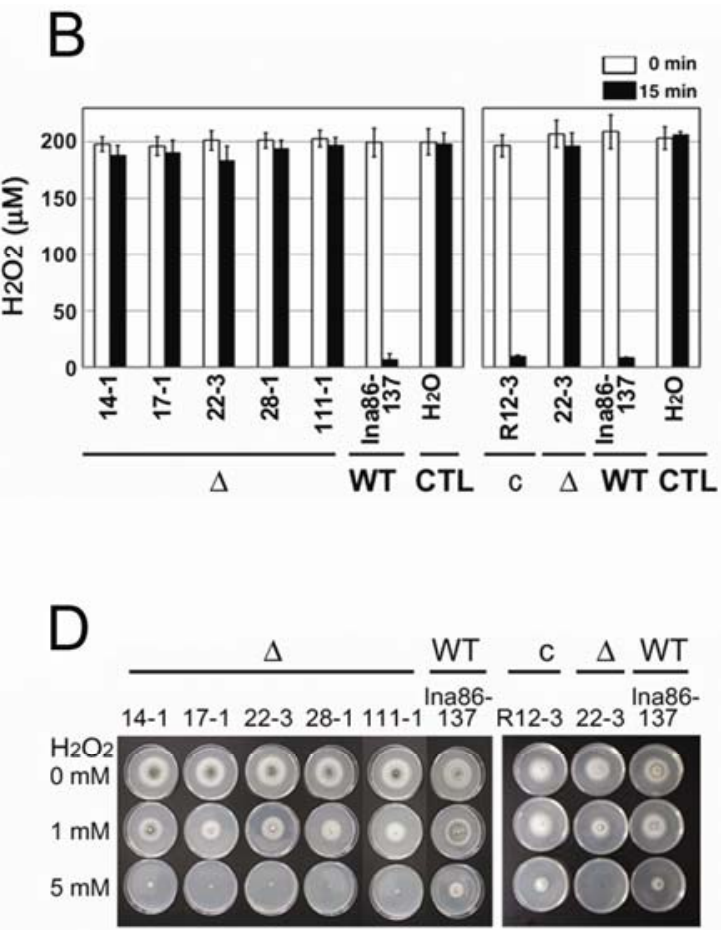

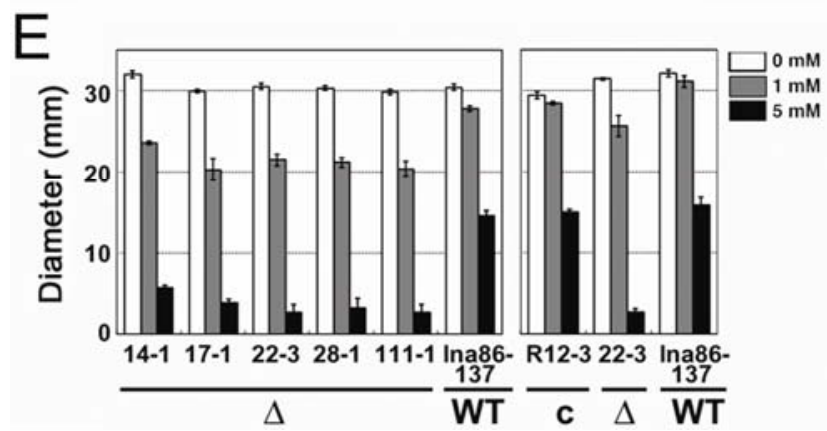

Fig. 3. Activity of secreted catalase and sensitivity to $\mathrm{H}_{2} \mathrm{O}_{2}$ in $\triangle C P X B$. A, Activity staining of secreted catalase in the potato dextrose agar (PDA). The strains of $\triangle C P X B$ s $(14-1,17-1,22-3,28-1$, the 111-1), $c C P X B$ (R12-3), and the control (WT; Ina86-137) were incubated on a nylon membrane laid on the PDA plate, which was stained for catalase activity. B, In vitro activity of catalase in the culture filtrate. Culture filtrates of strains as in A were gel filtered, concentrated, and incubated in the presence of $\mathrm{H}_{2} \mathrm{O}_{2}$. Open and closed bars indicate the residual $\mathrm{H}_{2} \mathrm{O}_{2}$ before and after incubation, respectively. Values represent the averages of three measurements \pm standard deviation (SD). CTL indicates distilled water. $\mathbf{C}$, In vitro activity of catalase in the supernatant of conidial suspension (SCS). SCS prepared from strains as in A were subjected to catalase assay. Open and closed bars indicate the residual $\mathrm{H}_{2} \mathrm{O}_{2}$ before and after incubation, respectively. Values represent the averages of three measurements \pm SD. CTL indicates distilled water. D, Hyphal growth of $\triangle C P X B$ on PDA plates containing $\mathrm{H}_{2} \mathrm{O}_{2}$. Strains as in A were inoculated on plates including $\mathrm{H}_{2} \mathrm{O}_{2}$ at the concentrations indicated and incubated for 5 days. A representative photograph is shown. E, Quantitative measurement of D. Each strain was incubated as in D, and the colony diameters were measured at 5 days postinoculation. Open, hatched, and closed bars indicate the diameter of colonies on PDA agar plates containing $\mathrm{H}_{2} \mathrm{O}_{2}$ at 0,1 , and 5 mM $\mathrm{H}_{2} \mathrm{O}_{2}$, respectively. Values represent the averages of five trials \pm SD. A, through $\mathbf{E}$, Experiments using the complemented line were separately conducted and shown in the right panels or rectangles. 
of M. oryzae on leaves of barley for up to $20 \mathrm{~h}$. Because the results in Figure 5B showed the delay in the infection rate of $\triangle C P X B$ at 20 to $29 \mathrm{hpi}$, we reexamined the expression level of $C P X B$ in leaf sheath of rice (Fig. 6). The $C A T B$ mRNA drastically accumulated at 6 hpi (approximately 15-fold higher than that at $0 \mathrm{hpi}$ ), then decreased at $48 \mathrm{hpi}$, basically the same results as in the previous report (Skamnioti et al. 2007). For $C P X A$ and $C P X B$, the level of mRNA was the highest at 6 and 3 hpi followed by decreases until 29 and $40 \mathrm{hpi}$, respectively. These results were different from those in barley leaves, where $C P X A$ and $C P X B$ showed a rapid suppression at 5 hpi followed by a transient activation at 12 hpi (Skamnioti et al. 2007).

\section{DISCUSSION}

Roles of fungal catalase in the pathogenicity.

The role of $\mathrm{H}_{2} \mathrm{O}_{2}$ has been demonstrated to be a molecular signal to a set of defense responses by the host plant infected with pathogens (Torres and Dangl 2005; Torres et al. 2006). It has been implicated as a chemical barrier against hemibiotrophic fungi. The rate of penetration by Colletotrichum coccodes was drastically enhanced by pretreatment of tomato leaves with catalase, concomitant with a reduction in the levels of $\mathrm{H}_{2} \mathrm{O}_{2}$ (Mellersh et al. 2002). Similarly, in wheat leaves inoculated with Septoria tritici, penetration rate and formation of lesions were enhanced or suppressed by pretreatment of leaves with catalase or $\mathrm{H}_{2} \mathrm{O}_{2}$, respectively (Shetty et al. 2007). These results, in addition to the present study, support the idea that accumulation of $\mathrm{H}_{2} \mathrm{O}_{2}$ is a crucial defense mechanism against these pathogens via its toxic action. To our knowledge, functional analysis of catalase by generating knockout mutants has not been undertaken in hemibiotrophic fungi, apart from Cat2 in Cladosporium fulvum (Bussink and Oliver 2001) and CATB of M. oryzae (Skamnioti et al. 2007).

In the biotrophic pathogen Claviceps purpurea, a transcriptional factor, $C P T F 1$, regulates the expression of genes for catalase, and its deficient mutant exhibited reduced pathogenicity (Nathues et al. 2004). Similar results were obtained in Ustilago maydis, where a knockout mutant of YAP1, a regulator of the responses to oxidative stress, was shown to be drastically impaired in pathogenicity. Two genes putatively regulated by $Y A P 1$, including a gene for peroxidase, were identified, and the knockout mutants of both genes exhibited much reduced virulence, comparable with that of the YAP1-deficient mutant. Inoculation of the mutant deficient in YAP1-regulated peroxidase induced the accumulation of $\mathrm{H}_{2} \mathrm{O}_{2}$ in the vicinity of hyphae, as observed when inoculated with the YAP1-deficient mutant (Molina and Kahmann 2007). These observations indicate that ROS-degrading activity is linked to pathogenicity in these fungi.

In contrast, roles of ROS-degrading enzymes in the necrotrophic fungi examined so far seem not so essential to the pathogenicity. For example, in Cochliobolus heterostrophus, mutants of a gene for catalase, CAT3, and for an AP1-like transcriptional factor, CHAP1, were more sensitive to extracellular $\mathrm{H}_{2} \mathrm{O}_{2}$ without a reduction in pathogenicity (Lev et al. 2005; Robbertse et al. 2003). In B. cinerea, a mutant deficient in a gene for an extracellular catalase (Bccat2) was generated and subjected to the electron microscopic observation after treatment with cerium chloride that detects $\mathrm{H}_{2} \mathrm{O}_{2}$, showing that the infected hyphae was directly exposed to $\mathrm{H}_{2} \mathrm{O}_{2}$ in planta. However, the mutant still exhibited full virulence (Schouten et al. 2002), indicating that $B$. cinerea has mechanisms other than extracellular catalase that confer tolerance to oxidative stress via $\mathrm{H}_{2} \mathrm{O}_{2}$. One possible reason why these studies did not prove a positive role for extracellular catalase in pathogenicity is that virulence was tested by lesion formation, which is not sensi- tive enough to detect subtle differences in the infection process, as already argued (Robbertse et al. 2003) and as demonstrated in this study (Fig. 5B and C).

\section{Biochemical features of CPXB.}

In this study, we partially purified the catalase activity from a culture filtrate of $M$. oryzae, obtained its internal amino acid sequence, and identified the gene as $C P X B$. The MW estimated by SDS-PAGE (Fig. 1) was larger than that calculated from the deduced amino acid sequence. At present, the reason for this inconsistency is not clear. It may be due to the post-translational modification of CPXB, such as glycosylation. In fact, the deduced amino acid sequence of CPXB includes seven potential $N$-glycosylation sites (Fig. 1B), implying that the inconsistency in the MW might be due to glycosylation of the mature protein. Glycosylation in the fungal extracellular peroxidase has been reported or suggested (Garre et al. 1998; Nie et al. 1999; Schreiber et al. 2008; Sugano et al. 1999) and is considered to increase thermostability (Nie et al. 1999). The catalase activity of CPXB was stable at room temperature (data not shown) and in the presence of SDS (Fig. 1); therefore, the glycosylation of CPXB might contribute to the stable conformation in these conditions.
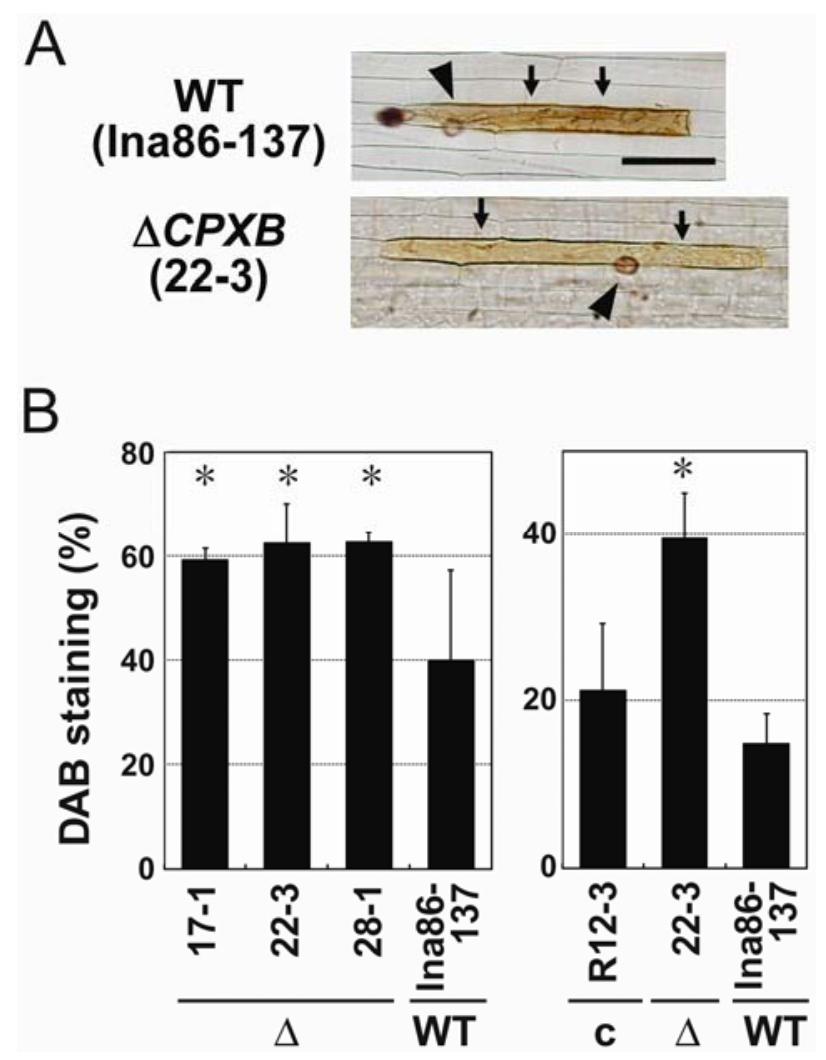

Fig. 4. Accumulation of $\mathrm{H}_{2} \mathrm{O}_{2}$ in the epidermal cells of leaf sheaths inoculated with $\triangle C P X B$. A, Representative 3',3-diaminobenzidine tetrahydrochloride (DAB)-staining patterns in the epidermal cell of the leaf sheath of rice cv. Nipponbare inoculated with the strain of control (WT; Ina86-137) or $\triangle C P X B(22-3)$ at $24 \mathrm{~h}$ postinoculation (hpi). Arrowheads and arrows indicate appressoria and infectious hyphae, respectively. A bar indicates 30 $\mu \mathrm{m}$. B, Number of appressoria that induced DAB-positive signals in the epidermal cells of leaf sheaths. The strains of $\triangle C P X B(\Delta ; 17-1,22-3,28-$ 1), $c C P X B$ ( $c$; R12-3), and control (WT; Ina86-137) were inoculated to the leaf sheath of rice cv. Nipponbare. More than 100 appressoria per leaf sheath were observed at $24 \mathrm{hpi}$, and the number of appressoria with DAB signals directly beneath them was counted. Asterisks indicate a significant difference from Ina86-137 based on Dunnett's test at $P<0.05$. Values represent the averages of five measurements \pm standard deviation. An experiment using the complemented line was separately conducted and shown in the right rectangles in each column. 
Roles of catalase in the pathogenicity of M. oryzae.

Among four catalase genes of $M$. oryzae, CATB was shown to contribute to the integrated architecture of the cell wall over the life cycle of the fungus, indicating that the regulation of the fungus-derived ROS is essential to the pathogenicity (Skamnioti et al. 2007). The hypothesis is supported by the observation that ROS production is required for the morphogenesis of appressoria and penetration through the host cuticle in M. oryzae (Egan et al. 2007). In a hemibiotroph, Colletotrichum acutatum, increase of the protein level of a catalase-peroxidase was detected at the stage of appressorium formation, which was tightly linked to the level of intracellular ROS, indicating that the gene is involved in pathogenicity through the regulation of ROS produced by the fungus (Brown et al. 2008).

An $M$. oryzae mutant, des 1 , was shown to be deficient in pathogenicity, which was restored by treatment of the rice leaf sheath with diphenylene iodinium, an inhibitor of NADPH- oxidase involved in the generation of ROS in plants (Chi et al. 2009). Mutant des 1 was highly sensitive to $\mathrm{H}_{2} \mathrm{O}_{2}$ in correlation with the lack of extracellular activity of peroxidase and laccase, and the expression of $C P X B$ was downregulated in desl, although the extracellular activity of catalase was not tested (Chi et al. 2009). Taking the results in Figure 3 into consideration, it cannot be excluded that DES1 confers resistance to extracellular $\mathrm{H}_{2} \mathrm{O}_{2}$ through $C P X B$. DES1 is a vacuole-localized protein, and its other biochemical properties are not clear, including how DES1 regulates these genes (Chi et al. 2009).

A detailed histological study showed that the primary invasion by $M$. oryzae is biotrophic and invaded cells are dead after the hypha move into the adjacent cells (Kankanala et al. 2007). Therefore, the necrotrophic phase is considered to start when Multi-cell infection is observed, whereas One-cell infection indicates that the infection stays at biotrophic phase. In this context, the results in Figure 5, showing that the effect of disruption of $C P X B$ on the infection was restricted before $29 \mathrm{hpi}$,

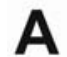

(a) Multi-cells

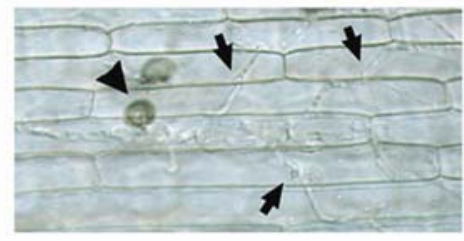

$20 \mathrm{~h}$

B

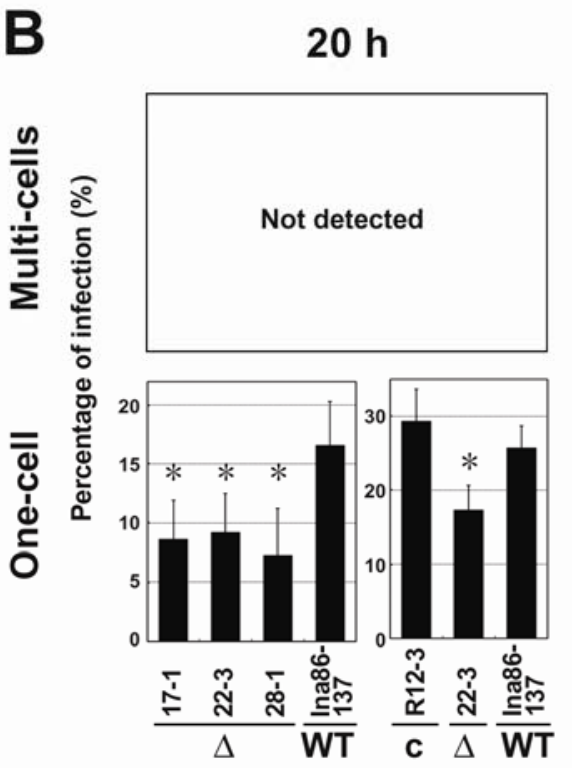

B (b) One-cell

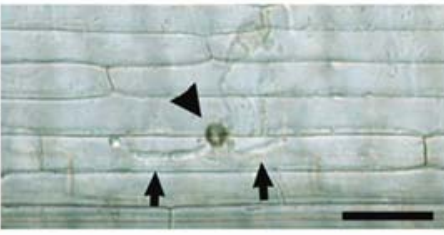

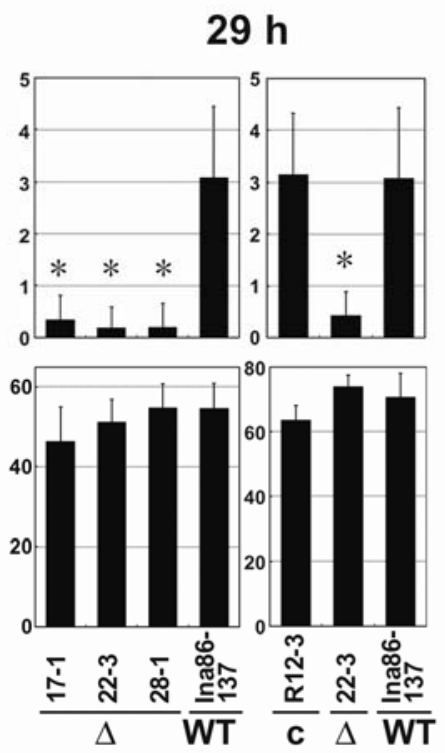

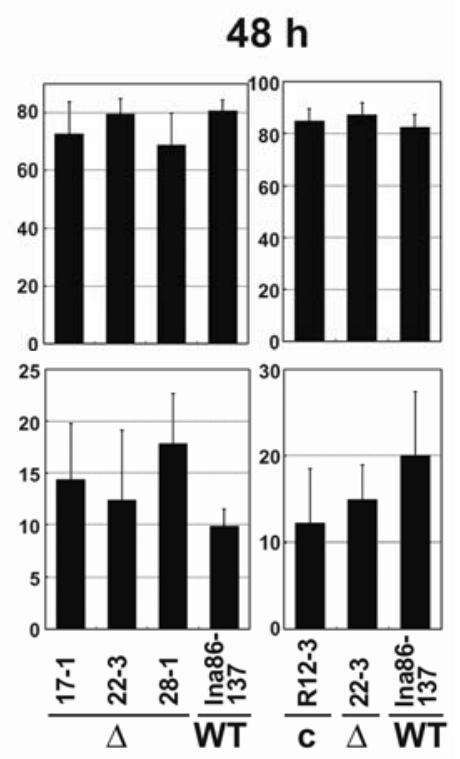

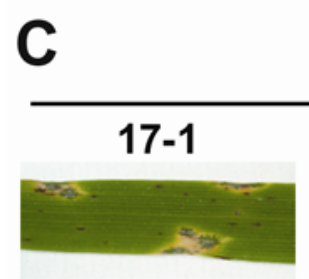

$\triangle C P X B$

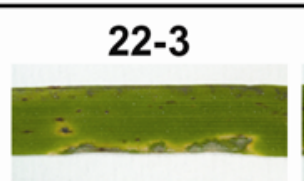

28-1

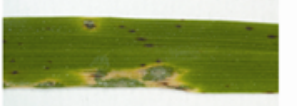

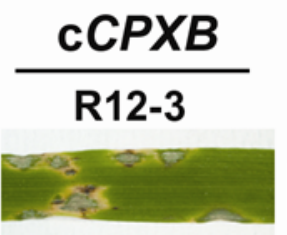

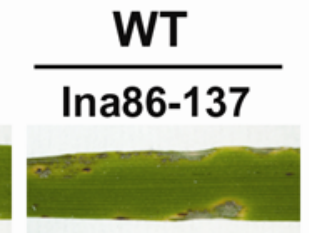

Fig. 5. Infection by $\triangle C P X B$ of the epidermal cells of the leaf sheath. A, Representative photographs of "multi-cells" infection and "one-cell" infection. Arrowheads and arrows indicate appressoria and infectious hyphae, respectively. A bar indicates $30 \mu \mathrm{m}$. B, Percentage of multi-cells and one-cell infection by $\triangle C P X B$. Conidial suspensions of $\triangle C P X B(\triangle ; 17-1,22-3,28-1), c C P X B(c ; \mathrm{R} 12-3)$, and a control strain (WT; Ina86-137) were inoculated to five-leaf sheaths, and the infection status of more than 100 appressoria per leaf sheath was scored at 20,29, and $48 \mathrm{~h}$ postinoculation. Asterisks in each panel indicate a significant difference from Ina86-137 based on Dunnett's test at $P<0.05$. Values represent the averages of five measurements \pm standard deviation. Experiments using the complemented line were separately conducted and shown in the right rectangles in each column. C, Lesions on a leaf blade sprayed with conidial suspensions of $\triangle C P X B(17-1,22-3,28-1), c C P X B$ (R12-3), and a control strain (WT; Ina86-137) at 7 days postinoculation. 
indicate that $C P X B$ promotes infection in the biotrophic phase. The expression of $C P X B$ in the leaf sheath of rice was transiently upregulated at 3 hpi (Fig. 6), preceding the accumulation of $\mathrm{H}_{2} \mathrm{O}_{2}$ in the epidermal cells of the rice leaf sheath at 6 hpi (Tanabe et al. 2009). Based on these observations, it is hypothesized that $C P X B$ plays antioxidative roles against the host-produced $\mathrm{H}_{2} \mathrm{O}_{2}$ at the biotrophic phase, and the sensitivity to $\mathrm{H}_{2} \mathrm{O}_{2}$ is reduced as infection proceeds to the necrotrophic phase, which is independent of $C P X B$. This hypothesis accounts for the unaltered pathogenicity of $\triangle C P X B$ in lesion formation at $6 \mathrm{dpi}$ (Fig. 5C). In the previous study, addition of exogenous catalase to the washed conidia of rice blast fungus enhanced the size of lesion in leaf blade (Tanabe et al. 2009). The observation might indicate that, at the late stage of infection, removal of $\mathrm{H}_{2} \mathrm{O}_{2}$ still supports fungal infection; however, $M$. oryzae acquires tolerance to $\mathrm{H}_{2} \mathrm{O}_{2}$ by other means than catalase.

\section{MATERIALS AND METHODS}

\section{Fungal materials and growth conditions.}

M. oryzae wild-type isolates Ina86-137 (race; 007.0, MAFF number 101511) and P91-15B (race; 001.0) were grown on oatmeal agar plates at $26^{\circ} \mathrm{C}$. A conidial suspension was prepared as described previously (Koga 1994). The washed conidia were obtained from the conidial suspension by centrifugation (twice) and were resuspended in distilled and sterile water (washed conidial suspension) as described previously (Tanabe et al. 2008). To test for sensitivity to $\mathrm{H}_{2} \mathrm{O}_{2}$, the fungi were cultured for 5 days at $26^{\circ} \mathrm{C}$ on PDA plates (Sigma-Aldrich Inc., St Louis) containing $\mathrm{H}_{2} \mathrm{O}_{2}$. For detection of catalase activity on agar plates, the fungi were grown for 5 days at $26^{\circ} \mathrm{C}$ on a nylon membrane laid on the surface of the PDA plate. After removal of the membrane, the agar plate was stained for catalase activity as described below. To analyze the secreted catalase, M. oryzae was cultured in YG medium (2\% [wt/vol] yeast extract and $0.5 \%[\mathrm{wt} / \mathrm{vol}]$ glucose) at $25^{\circ} \mathrm{C}$ with rotation at 120 rpm.

Plant material, inoculation, and in situ detection of $\mathrm{H}_{2} \mathrm{O}_{2}$.

Rice seedlings (Oryza sativa cv. Nipponbare) were grown in hydroponic culture for 3 weeks as described previously (Tanabe et al. 2006), sprayed with a conidial suspension $\left(1 \times 10^{5}\right.$ conidia $/ \mathrm{ml}$ ), and incubated at $20^{\circ} \mathrm{C}$ in a moist chamber for $24 \mathrm{~h}$, then transferred to a greenhouse at $25^{\circ} \mathrm{C}$ for 7 days. For the leaf sheath assay, excised leaf sheaths were covered with the washed conidial suspension $\left(1 \times 10^{5}\right.$ conidia/ml $)$ and incubated at $25^{\circ} \mathrm{C}$ for the times indicated (Koga 1994). For the in situ detection of $\mathrm{H}_{2} \mathrm{O}_{2}$, the leaf sheaths were stained with a solution of DAB at $1 \mathrm{mg} / \mathrm{ml}$ for $12 \mathrm{~h}$ (Thordal-Christensen et al. 1997). For evaluation of hyphal infection in epidermal cells of the leaf sheaths, the inoculated leaf sheaths were fixed in $45 \%$ (vol/vol) ethanol, 5\% (vol/vol) acetic acid, and $1.85 \%$ (vol/vol) formaldehyde; intact appressoria were counted under a microscope; and the extent of infection was scored as multi-cells or one-cell by counting the number of appressorium beneath which infectious hyphae were observed in more than one cell or one cell, respectively.

\section{Partial purification of catalase from the culture fluid.}

P91-15B was cultured in YG medium at $25^{\circ} \mathrm{C}$ for 15 days, and the medium was filtered through Miracloth (Calbiochem, La Jolla, CA, U.S.A.). Total soluble and insoluble protein at 50 and $70 \%$ saturation with $\left(\mathrm{NH}_{4}\right)_{2} \mathrm{SO}_{4}$, respectively, was recovered by centrifugation at $10,000 \times g$ for $30 \mathrm{~min}$ at $4^{\circ} \mathrm{C}$. The resultant pellet was dissolved in water and desalted with Sephadex G-75 column chromatography, equilibrated with 10 $\mathrm{mM}$ Tris- $\mathrm{HCl}(\mathrm{pH} 7.5)$. The fractions having catalase activity were collected, applied to a DEAE cellulose column equilibrated with $10 \mathrm{mM}$ Tris- $\mathrm{HCl}(\mathrm{pH} 7.5)$, washed with $10 \mathrm{mM}$ Tris- $\mathrm{HCl}$ containing $50 \mathrm{mM} \mathrm{NaCl}(\mathrm{pH} 7.5)$, and eluted with 10 $\mathrm{mM}$ Tris- $\mathrm{HCl}$ containing $100 \mathrm{mM} \mathrm{NaCl}(\mathrm{pH}$ 7.5). Fractions were combined, concentrated in vacuo, and dissolved in water, followed by desalting with Sephadex G75 column chromatography equilibrated with water. After concentration in vacuo, the proteins were separated by SDS-PAGE on 5 to $20 \%$ polyacrylamide gel, and the band stained with Coomassie brilliant blue R-250 with the same mobility as that stained for catalase activity was excised. Peptide fragments obtained by digestion with lysyl endopeptidase were subjected to the Edman degradation method.

\section{Generation of a $C P X B$-deficient mutant and its complement.}

Generation of a $C P X B$-deficient mutant was carried out as previously described (Saitoh et al. 2008). The 5'-end fragment that starts with the putative initiation codon (1,330 bp) and the 3 '-end fragment that ends with the putative termination codon $(1,124 \mathrm{bp})$ of $C P X B$ were amplified by polymerase chain reac-
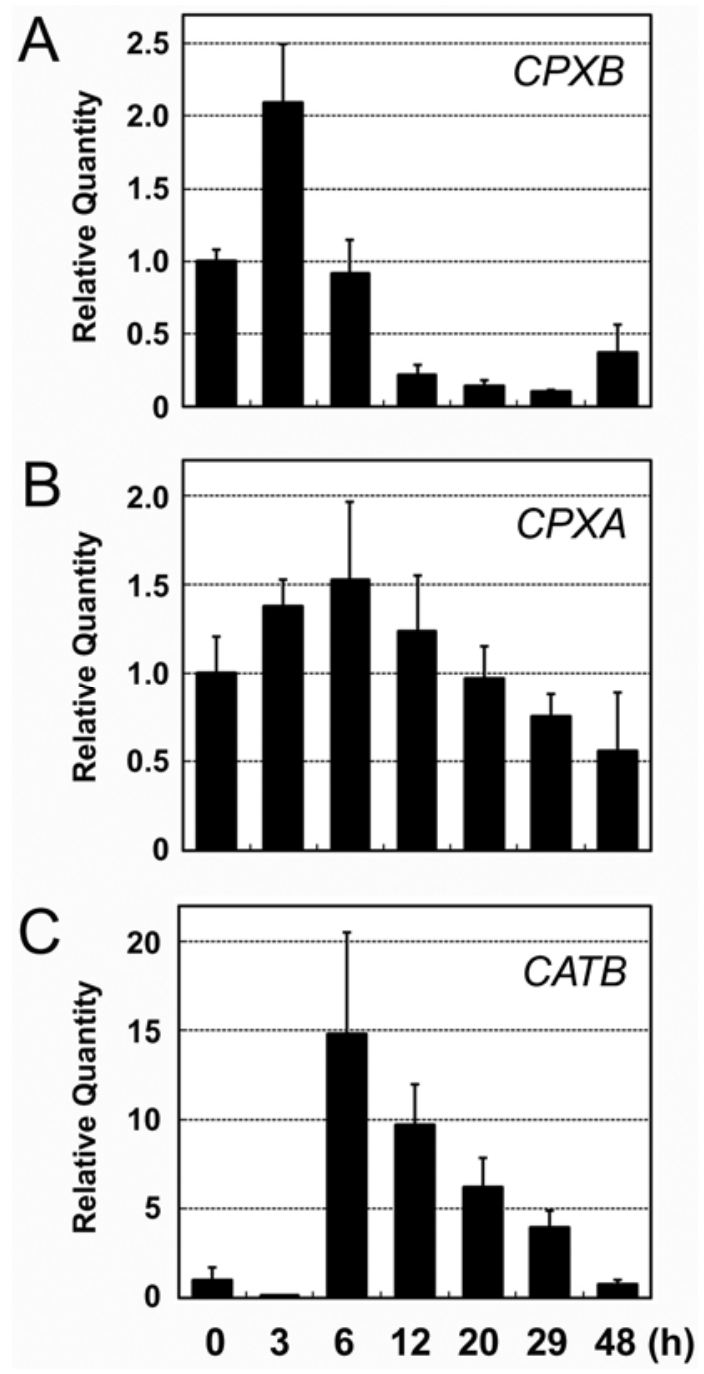

Fig. 6. Changes in the levels of mRNAs from $C P X A, C P X B$, and $C A T B$ of Ina86-137 during infection in the rice leaf sheath. Total RNAs were extracted from the leaf sheath of rice inoculated with Ina86-137 at the time indicated, and the relative level of mRNA for $\mathbf{A}, C P X B ; \mathbf{B}, C P X A$; and $\mathbf{C}$, $C A T B$ was measured by quantitative reverse-transcription polymerase chain reaction and normalized using the expression levels of $28 \mathrm{~S}$ rRNA of Magnaporthe oryzae. 
tion (PCR) using primer combinations F1/R1 and F2/R2, respectively. The nucleotide sequences of the primers were F1, 5'-CCAAGCTTATGCACGCATCACTCTCTCAAG-3'; R1, 5' CCCAAGCTTCCCATGAGATCTTGTTGCCA-3'; F2, 5'-CA AGTTCCGCAAGGCTACCA-3'; and R2, 5'-TTATTTCTTGA CCTTGAGGTCGA-3'. After verifying the amplified sequences, both fragments were cloned into the entry vector $\mathrm{pETH}$ to construct $\mathrm{pETH}-C P X B-\mathrm{KO}$. pCAMBIA- $C P X B-\mathrm{KO}$ was generated by the LR reaction of pETH-CPXB-KO with pCAMBIABar-RfA and introduced into $M$. oryzae isolate Ina86-137 via Agrobacterium tumefaciens EH105, followed by selection as previously described (Saitoh et al. 2008).

For complementation of $\triangle C P X B$, the genomic DNA fragment containing the protein coding region $(2,006 \mathrm{bp})$ and 5 '-flanking region upstream of putative initiation codon (219 bp) was amplified by PCR. After verifying by sequencing, the fragment was ligated to PtrpC promoter and inserted upstream of Tnos in pCAMBIA-0380 with the PtrpC-Bar fragment. The resultant binary vector, pCAMBIA- $c C P X B$, was used for transformation of $\triangle C P X B$.

To verify the genomic recombination, Southern blot analysis was carried out using a ${ }^{32} \mathrm{P}$-labeled genomic fragment (559 to $1,330)$ as a probe, which was amplified by PCR using primers F3 (5'-ATGCACGCATCACTCTCAAG-3') and R3 (5'-CCCA TGAGATCTTGTTGCCA-3').

\section{Catalase assay.}

An in-gel assay of catalase activity was performed as described by Woodbury and associates (1971). For measurement of catalase activity, $1 \mathrm{ml}$ of $200 \mu \mathrm{M} \mathrm{H}_{2} \mathrm{O}_{2}$ was incubated with the culture filtrate or SCS containing $5 \mu \mathrm{g}$ of protein at $25^{\circ} \mathrm{C}$ for $15 \mathrm{~min}$, and the residual $\mathrm{H}_{2} \mathrm{O}_{2}$ was determined by the luminol method (Schwacke and Hager 1992). The protein concentration of the culture filtrates and SCS were determined using a Coomassie (Bradford) protein assay kit (Thermo Fisher Scientific Inc., Rockford, IL, U.S.A.). SCS was prepared from the conidial suspension as described previously (Tanabe et al. 2008).

\section{Analysis of expression of fungal genes in planta.}

The leaf sheath of Nipponbare was inoculated with a conidial suspension $\left(1 \times 10^{5}\right.$ conidia/ml $)$ of Ina86-137 and total RNA was isolated using the RNeasy Plant Kit (Qiagen, Valencia, CA, U.S.A.). The expression of fungal genes was investigated by quantitative reverse-transcription PCR as described previously (Kato et al. 2009). The gene expression levels were normalized using 28S ribosomal RNA gene (GenBank accession number AF362554). The nucleotide sequences of the primers were F, 5'-GGGGCGATTTTTAGCCTTCA-3'; and R, $5^{\prime}$-ATTCGAAGGCCCACGTTCAA-3'. The primers for the detection of the mRNAs for CPXA, CPXB and CATB of rice blast fungus were designed according to Skamnioti and associates (2007).

\section{ACKNOWLEDGMENTS}

M. oryzae isolate P91-15B was provided by H. Naitoh of Akita Prefectural Unversity, Japan. A Japanese isolate of M. oryzae, Ina86-137 (MAFF 101511), was supplied by NIAS Genebank. This study was supported by the Program for Promotion of Basic Research Activities for Innovative Biosciences.

\section{LITERATURE CITED}

Able, A. J. 2003. Role of reactive oxygen species in the response of barley to necrotrophic pathogens. Protoplasma 221:137-143.

Bradley, D. J., Kjelbom, P., and Lamb, C. J. 1992. Elicitor- and woundinduced oxidative cross-linking of a proline-rich plant cell wall protein:
A novel, rapid defense response. Cell 70:21-30.

Brown, S. H., Yarden, O., Gollop, N., Chen, S., Zveibil, A., Belausov, E., and Freeman, S. 2008. Differential protein expression in Colletotrichum acutatum: Changes associated with reactive oxygen species and nitrogen starvation implicated in pathogenicity on strawberry. Mol. Plant Pathol. 9:171-190.

Bussink, H.-J., and Oliver, R. 2001. Identification of two highly divergent catalase genes in the fungal tomato pathogen, Cladosporium fulvum. Eur. J. Biochem. 268:15-24.

Chai, H. B., and Doke, N. 1987. Activation of the potential of potato leaf tissue to act hypersensitively to Phytophthora infestans by calcium ions. Physiol. Mol. Plant Pathol. 30:27-37.

Chi, M.-H., Park, S.-Y., Kim, S., and Lee, Y.-H. 2009. A novel pathogenicity gene is required in the rice blast fungus to suppress the basal defenses of the host. PLoS Pathog. 5:e1000401. Published online.

Dean, R. A., Talbot, N. J., Ebbole, D. J., Farman, M. L., Mitchell, T. K., Orbach, M. J., Thon, M., Kulkarni, R., Xu, J.-R., Pan, H., Read, N. D., Lee, Y.-H., Carbone, I., Brown, D., Oh, Y. Y., Donofrio, N., Jeong, J. S., Soanes, D. M., Djonovic, S., Kolomiets, E., Rehmeyer, C., Li, W., Herding, M., Kim, S., Lebrum, M.-H., Bohnert, H., Coughlan, S., Butler, J., Calvo, S., Ma, L.-J., Nicol, R., Purcell, S., Nusbaum, C., Galagan, J. E., and Birren, B. W. 2005. The genome sequence of the rice blast fungus Magnaporthe grisea. Nature 434:980-986.

Doke, N. 1983. Involvement of superoxide anion generation in the hypersensitive response of potato tuber tissues to infection with an incompatible race of Phytophthora infestans and to the hyphal wall components. Physiol. Plant Pathol. 23:345-357.

Egan, M. J., Wang, Z.-Y., Jones, M. A., Smirnoff, N., and Talbot, N. J. 2007. Generation of reactive oxygen species by fungal NADPH oxidases is required for rice blast disease. Proc. Natl. Acad. Sci. U.S.A. 104:11772-11777.

Garre, V., Müller, U., and Tudzynski, P. 1998. Cloning, characterization, and targeted disruption of cpcatl, coding for an in planta secreted catalase of Claviceps purpurea. Mol. Plant-Microbe Interact. 11:772-783.

Govrin, E. M., and Levine, A. 2000. The hypersensitive response facilitates plant infection by the necrotrophic pathogen Botrytis cinerea. Curr. Biol. 10:751-757.

Howard, R. J., and Valent, B. 1996. Breaking and entering: Host penetration by the fungal rice blast pathogen Magnaporthe grisea. Annu. Rev. Microbiol. 50:491-512.

Kankanala, P., Czymmek, K., and Valent, B. 2007. Roles for rice membrane dynamics and plasmodesmata during biotrophic invasion by the blast fungus. Plant Cell 19:706-724.

Kato, T., Tanabe, S., Nishimura, M., Ohtake, Y., Nishizawa, Y., Shimizu, T., Jikumaru, Y., Koga, J., Okada, K., Yamane, H., and Minami, E. 2009. Differential responses of rice to inoculation with wild-type and non-pathogenic mutants of Magnaporthe oryzae. Plant Mol. Biol. 70:617625.

Kawasaki, T., Henmi, K., Ono, E., Hatakeyama, S., Iwano, M., Satoh, H., and Shimamoto, K. 1999. The small GTP-binding protein Rac is a regulator of cell death in plants. Proc. Natl. Acad. Sci. U.S.A. 96:1092210926.

Koga, H. 1994. Hypersensitive death, autofluorescence, and ultrastructural changes in cells of leaf sheaths of susceptible and resistant near-isogenic lines of rice $\left(P i-z^{t}\right)$ in relation to penetration and growth of Pyricularia oryzae. Can. J. Bot. 72:1463-1477.

Kumar, J., Hückelhoven, R., Beckhove, U., Nagarajan, S., and Kogel, K.H. 2001. A compromised Mlo pathway affects the response of barley to the necrotrophic fungus Bipolaris sorokiniana (teleomorph: Cochliobolus sativus) and its toxins. Phytopathology 91:127-133.

Lamb, C., and Dixon, R. A. 1997. The oxidative burst in plant disease resistance. Annu. Rev. Plant Physiol. Plant Mol. Biol. 48:251-275.

Lev, S., Hadar, R., Amedeo, P., Baker, S. E., Yoder, O. C., and Horwitz, B. A. 2005. Activation of an AP1-like transcription factor of the maize pathogen Cochliobolus heterostrophus in response to oxidative stress and plant signals. Eukaryot. Cell 4:443-454.

Lu, H., and Higgins, V. J. 1999. The effect of hydrogen peroxide on the viability of tomato cells and of the fungal pathogen Cladosporium fulvum. Physiol. Mol. Plant Pathol. 29:147-157.

Mellersh, D. G., Foulds, I. V., Higgins, V. J., and Heath, M. C. 2002. $\mathrm{H}_{2} \mathrm{O}_{2}$ plays different roles in determining penetration failure in three diverse plant-fungal interactions. Plant J. 29:257-268.

Molina, L., and Kahmann, R. 2007. An Ustilago maydis gene involved in $\mathrm{H}_{2} \mathrm{O}_{2}$ detoxification is required for virulence. Plant Cell 19:22932309.

Nathues, E., Joshi, S., Tenberge, K. B., von den Driesch, M., Oeser, B., Bäumer, N., Mihlan, M., and Tudzynski, P. 2004. CPTF1, a CREB-like transcription factor, is involved in the oxidative stress response in the phytopathogen Claviceps purpurea and modulates ROS level in its host Secale cereale. Mol. Plant-Microbe Interact. 17:383-393. 
Nie, G., Reading, N. S., and Aust, S. D. 1999. Relative stability of recombinant versus native peroxidases from Phanerochaete chrysoporium. Arch. Biochem. Biophys. 365:328-334.

Peng, M., and Kuc, J. 1992. Peroxidase-generated hydrogen peroxide as a source of antifungal activity in vitro and on tobacco leaf disks. Phytopathology 82:696-699.

Robbertse, B., Yoder, O. C., Nguyen, A., Schoch, C. L., and Turgeon, B. G. 2003. Deletion of all Cochliobolus heterostrophus monofunctional catalase-encoding genes reveals a role for one in sensitivity to oxidative stress but none with a role in virulence. Mol. Plant-Microbe Interact. 16:1013-1021.

Saitoh, K., Nishimura, M., Kubo, Y., Hayashi, N., Minami, E., and Nishizawa, Y. 2008. Construction of a binary vector for knockout and expression analysis of rice blast fungus genes. Biosci. Biotechnol. Biochem. 72:1380-1383.

Schouten, A., Tenberge, K. B., Vermeer, J., Stewart, J., Wagemakers, L. Williamson, B., and Van Kan, J. A. 2002. Functional analysis of an extracellular catalase of Botrytis cinerea. Mol. Plant Pathol. 3:227-238.

Schreiber, M., Hülsdau, B., Zelena, K., Nimtz, M., de Boer, L., Berger, R. G., and Zorn, H. 2008. Novel peroxidases of Marasmius scorodonius degrade $\beta$-carotene. Appl. Microbiol. Biotechnol. 77:1241-1250.

Schwacke, R., and Hager, R. 1992. Fungal elicitors induce a transient release of reactive oxygen species from cultured spruce cells that is dependent on $\mathrm{Ca}^{2+}$ and protein kinase activity. Planta 187:136-141.

Shetty, A. P., Mehrabi, R., Lütken, H., Haldrup, A., Kema, G. H. J., Collinge, D. B., and Jørgensen, H. J. L. 2007. Role of hydrogen peroxide during the interaction between the hemibiotrophic fungal pathogen Septoria tritici and wheat. New Phytol. 174:637-647.

Skamnioti, P., Henderson, C., Zhang, Z., Robinson, Z., and Gurr, S. J. 2007. A novel role for catalase B in the maintenance of fungal cell-wall integrity during host invasion in the rice blast fungus Magnaporthe grisea. Mol. Plant-Microbe Interact. 20:568-580.

Sugano, Y., Sasaki, K., and Shoda, M. 1999. cDNA cloning and genetic analysis of a novel decolorizing enzyme, peroxidase gene dyp from Geotrichum candidum Dec 1. J. Biosci. Bioeng. 87:411-417.

Talbot, N. J. 2003. On the trail of a cereal killer: Exploring the biology of Magnaporthe grisea. Annu. Rev. Microbiol. 57:177-202.

Tanabe, S., Okada, M., Jikumaru, Y., Yamane, H., Kaku, H., Shibuya, N., and
Minami, E. 2006. Induction of resistance against rice blast fungus in rice plants treated with a potent elicitor, $N$-acetylchitooligosaccharide. Biosci. Biotechnol. Biochem. 70:1599-1605.

Tanabe, S., Hayashi, N., Nishizawa, Y., Yamane, H., Shibuya, N., and Minami, E. 2008. Elicitor and catalase activity of conidia suspension of various strains of Magnaporthe grisea in suspension-cultured cells of rice. Biosci. Biotechnol. Biochem. 72:889-892.

Tanabe, S., Nishizawa, Y., and Minami. E. 2009. Effects of catalase on the accumulation of $\mathrm{H}_{2} \mathrm{O}_{2}$ in rice cells inoculated with rice blast fungus, Magnaporthe oryzae. Physiol. Plant. 137:148-154.

Thordal-Christensen, H., Zhang, Z., Wei, Y., and Collinge, D. B. 1997. Subcellular localization of $\mathrm{H}_{2} \mathrm{O}_{2}$ in plants. $\mathrm{H}_{2} \mathrm{O}_{2}$ accumulation in papillae and hypersensitive response during the barley-powdery mildew interaction. Plant J. 11:1187-1194.

Torres, M. A., and Dangl, J. L. 2005. Functions of the respiratory burst oxidase in biotic interactions, abiotic stress and development. Curr. Opin. Plant Biol. 8:397-403.

Torres, M. A., Jones, J. D. G., and Dangl, J. L. 2006. Reactive oxygen species signaling in response to pathogens. Plant Physiol. 141:373-378.

Tucker, S. L., and Talbot, N. J. 2001. Surface attachment and pre-penetration stage development by plant pathogenic fungi. Annu. Rev. Phytopathol. 39:385-417.

Vanacker, H., Carver, T. L. W., and Foyer, C. H. 2000. Early $\mathrm{H}_{2} \mathrm{O}_{2}$ accumulation in mesophyll cells leads to induction of glutathione during the hyper-sensitive response in the barley-powdery mildew interaction. Plant Physiol. 123:1289-1300.

Woodbury, W., Spencer, A. K., and Stahmann, M. A. 1971. An improved procedure using ferricyanide for detecting catalase isozymes. Anal. Biochem. 44:301-305.

\section{AUTHOR-RECOMMENDED INTERNET RESOURCES}

The Broad Institute Magnaporthe oryzae genome database: www.broad.mit.edu/annotation/fungi/magnaporthe

PSORT protein prediction server: psort.hgc.jp

NIAS Genebank database:

www.gene.affrc.go.jp/databases-micro_search_en.php 